\title{
Does the platelet-to-lymphocyte ratio have a prognostic effect in patients with myelodysplastic syndrome?
}

\author{
Yikilmaz AS ${ }^{1}$, Akinci $\mathrm{S}^{2}$, Bakanay $\mathrm{SM}^{1}$, Dilek $\mathrm{I}^{1}$ \\ Department of Hematology, Yildirim Beyazit University, Ankara, Turkey. senturkaysun@gmail.com
}

\begin{abstract}
INTRODUCTION: Myelodysplastic syndromes (MDS) include various hematologic abnormalities characterized by chronic cytopenia due to disruption in cellular differentiation. This study aims to evaluate the prognostic value of PLR in patients with MDS.

MATERIAL AND METHODS: Clinical-laboratory findings and the results of bone marrow biopsies of MDS patients before treatment were recorded. $p$ value of $<0.05$ was considered statistically significant. SPSS version 20.0 was used for statistical analysis.

RESULTS: The study included 62 patients with median follow-up time of $62.8 \pm 4.5$ months and median age of 68.5 years. In 13 patients, acute leukemia was transformed. In these subjects, a PLR cut-off level of 46 was established for mortality $(p=0.015)$. We found a significant relationship between PLR and multilineage series with the presence of dysplasia $(p=0.017)$. The survival analysis showed a decreased survival in cases with dysplasia in two and/or more series, transformation into acute leukemia, and thrombocytopenia. CONCLUSION: Our study demonstrated that there was a relationship between PLR and MDS with multilineage dysplasia (mld-MDS). PLR is investigated as an inflammatory finding in various hematologic malignancies. Further studies investigating the value of PLR in MDS are needed to determine whether PLR may be a marker of bone marrow dysplasia grading (Tab. 2, Fig. 4, Ref. 32). Text in PDF www.elis.sk. KEY WORDS: myelodysplastic syndromes, hematologic abnormalities, chronic cytopenia, cellular differentiation, marrow biopsy, acute leukemia, thrombocytopenia.
\end{abstract}

\section{Introduction}

Myelodysplastic syndromes (MDS) are hematological clonal neoplasms in which ineffective hematopoiesis occurs in one or more blood cell lineages due to dysmorphogenesis (1). MDS patients are at increased risk of transformation to acute myeloid leukemia. Defective hematopoiesis may lead to anemia, bleeding, and increased risk of infection. MDS presents as anemia in $85 \%$, neutropenia in $50 \%$, and thrombocytopenia and low lymphocyte count in $25-50 \%$ of cases at the time of diagnosis (2).

Scoring systems are usually used to determine the MDS prognosis. There are three different prognostic scoring systems for MDS determined by findings that include bone marrow blast percentage, karyotype, cytogenetics, degree of cytopenia, need for red blood cell transfusion, age, and performance status (3). In addition to the revised International Prognostic Scoring System (IPSS-R), WHO Prognostic Scoring System (WPSS), and MD

${ }^{1}$ Department of Hematology, Yildirim Beyazit University, Ankara, Turkey, and ${ }^{2}$ Department of Hematology, Ataturk Training And Research Hospital, Ankara, Turkey

Address for correspondence: A.S. Yikilmaz, MD, Department of Hematology, Yildirim Beyazit University, Bilkent Yolu 3. Km. Çankaya Ankara 06010, Turkey.

Phone: +905324600335, Fax: +903122912747
Anderson Cancer Center (MDACC) MDS model, many clinical and laboratory findings such as elevated ferritin levels, gene expression profiling, increased DNA methylation, increased serum beta- 2 microglobulin, and absolute lymphocyte count have been demonstrated to be effective in determining prognosis in MDS patients (4-7). Data from various publications have shown the prognostic impact of low absolute lymphocyte count and thrombocytopenia in $\operatorname{MDS}(8,9)$.

The role of inflammation in cancer biology has been reported with increasing evidence over the years. A complex relationship between host and tumor has been shown through certain mediators and inflammatory cells surrounding the cancer cell and its microenvironment. Biochemical findings such as $\mathrm{C}$-reactive protein, albumin, white blood cell count, and neutrophil count are frequently considered indicators of systemic inflammation (10). It is known that platelets also play a role in the systemic inflammatory response (11).

The effect of inflammation and immunological microenvironment on the pathogenesis of MDS was observed in recently published data (12). In studies involving low-risk MDS patients, T lymphocyte-mediated inhibition of hematopoiesis was observed. Subsequently, the escape from immune surveillance in the later phase of the disease has been shown to be effective in the transformation to acute leukemia. Both thrombocytopenia and decrease in absolute lymphocyte count have been suggested as poor prognostic markers in $\operatorname{MDS}(8,9)$. Although there are studies on the 


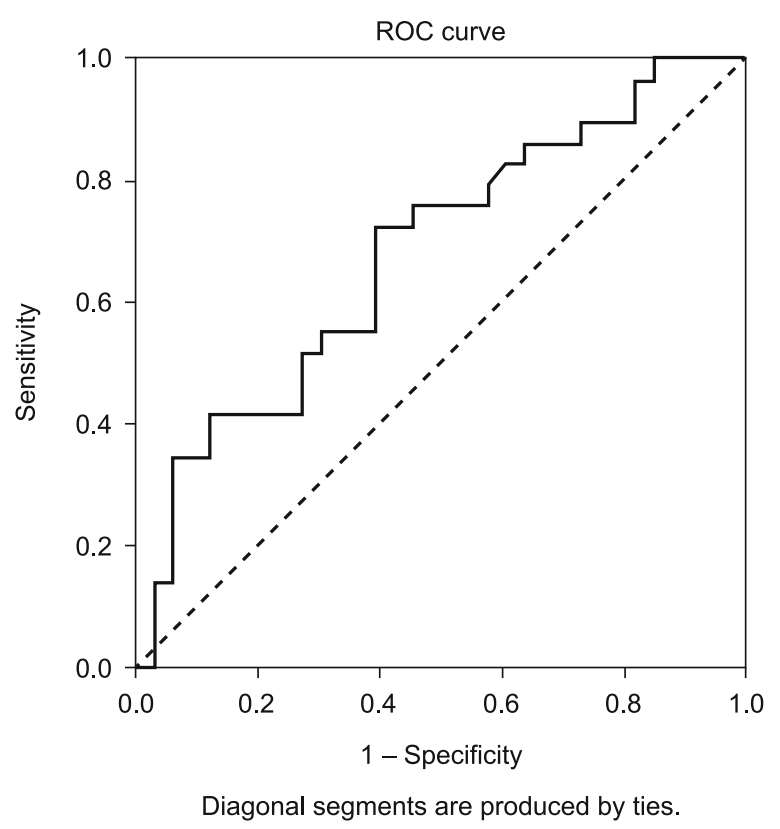

Fig. 1. Roc curve for PLR cut-off value and mortality.

prognostic value of PLR as an indicator of inflammation in both hematologic and solid malignancies (13-16), we did not encounter any study examining PLR in MDS. In this study, we aimed to investigate whether or not PLR is associated with clinical and laboratory findings, prognosis, and leukemic transformation in MDS.

\section{Material and methods}

\section{Patients}

The clinical data of 62 cases of MDS diagnosed at the Yildirim Beyazit University Hospital, Department of Hematology between 2009 to 2018 were retrospectively examined. Laboratory values measured at initial MDS diagnosis were examined. Bone marrow biopsies performed during diagnosis were reviewed. The subtypes of MDS were defined by using the World Health Organization (WHO) classification system (17).

\section{Clinical data}

The demographic data and clinicopathologic features of patients were collected from medical records, including MDS subtype, lactate dehydrogenase (LDH), blood tests, and pathology reports. Leukocyte, lymphocyte, platelet, and neutrophil counts were recorded from standard hemogram results before the initiation of any treatment (pretreatment). PLR was calculated as the absolute platelet count divided by the absolute lymphocyte count. ROC curves were used to determine the best threshold values for sensitivity and specificity. in MDS cases.

\section{Statistical analysis}

SPSS (Statistical Package for Social Sciences) version 15.0 for Windows was used for statistical analysis. Student's t-test and Chi-square tests were used in addition to descriptive statistics when applicable. Kaplan-Meier's curves were used for overall survival analysis and receiver operating characteristic (ROC) curves were formulated to estimate the cut-off level of PLR for mortality. The Cox proportional hazards model was used for the independent variables affecting overall survival (categorical values consisting of two simple ordinal numbers). $\mathrm{p}<0.05$ was considered statistically significant.

\section{Results}

A total of 62 patients diagnosed with MDS were included in this study. The median age of MDS cases was 68.5 ( $\min 35$, max $89)$ years. Male/female ratio was $41 / 21$ (63.1\%/36.9\%). There were 37 (59.7\%) patients over 65 years of age. Median follow up time was $62.8 \pm 4.5$ months. There were $26(41.9 \%)$ cases with multilineage dysplasia (mld-MDS), 17 (27.4\%) cases with single lineage dysplasia, 16 (25.8\%) with excess blasts, and 3 (4.8\%) cases with ring sideroblasts.

At the time of initial diagnosis, mean hemoglobin value was $8.4 \pm 1.94 \mathrm{gr} / \mathrm{dL}$, median platelet count was $135.5 \times 10^{9} / \mathrm{L}$ (min: $5 \times 10^{9} / \mathrm{L}$ max: $\left.425 \times 10^{9} / \mathrm{L}\right)$, median leukocyte count was $3.3 \times 10^{9} / \mathrm{L}$ (min: $0.6 \times 10^{9} / \mathrm{L} \max : 9.9 \times 10^{9} / \mathrm{L}$ ), and median lymphocyte count was $1.13 \times 10^{9} / \mathrm{L}$ (min:0.15 x10\%/L max:5.16 x109/L). Bone marrow blast percentage was below $5 \%$ in $46(74.2 \%)$ cases, $5-10 \%$ in $12(19.4 \%)$, and between 11 and $20 \%$ in $4(6.5 \%)$ cases. Of the $12(19.4 \%)$ MDS cases with ring sideroblasts, the percentage of ring sideroblasts in bone marrow was above $15 \%$ in $6(9.7 \%)$ patients and below $15 \%$ in $6(9.7 \%)$ patients. MDS cases with single and two and/or more series dysplasia in bone marrow were 27 (43.5\%) and 35 (56.5\%), respectively. There were 40 (61.5\%) cases of bone marrow pathology consisting of grade 1-3 fibrosis, and $25(38.4 \%)$ cases without fibrosis. Thirteen $(20 \%)$ patients underwent transformation into acute myeloid leukemia, and 33 $(53.2 \%)$ patients died.

Tab. 1. Comparison of clinical and laboratory findings according to PLR cut-off value of 46

\begin{tabular}{lccc}
\hline Platelet/lymphocyte ratio & $\begin{array}{c}\text { PLR }>46 \\
(\mathrm{n}=39(62.9 \%))\end{array}$ & $\begin{array}{c}\text { PLR } \leq 46 \\
(\mathrm{n}=23(37.1 \%))\end{array}$ & $\mathrm{p}$ \\
\hline Blast percentage $<5 \%$ & $29(63 \%)$ & $17(37 \%)$ & 0.598 \\
\hline Neutrophil $<1500 / \mu \mathrm{L}$ & $10(50 \%)$ & $10(20 \%)$ & 0.121 \\
\hline Hemoglobin $<10 \mathrm{~g} / \mathrm{dL}$ & $38(63.3 \%)$ & $22(36.7 \%)$ & 0.608 \\
\hline Hemoglobin $<8 \mathrm{~g} / \mathrm{dL}$ & $28(68.3 \%)$ & $13(31.7 \%)$ & 0.171 \\
\hline Bone marrow fibrosis & $27(62.8 \%)$ & $16(37.2 \%)$ & 0.609 \\
\hline $\begin{array}{l}\text { Cases with MDS with multilineage } \\
\text { dysplasia }(\text { mld-MDS) }\end{array}$ & $17(48.6 \%)$ & $18(51.4 \%)$ & 0.008 \\
\hline Ring sideroblasts in bone marrow & $8(66.7 \%)$ & $4(33.3 \%)$ & 0.520 \\
\hline Gender M/F & $27(43.5 \%) / 12(19.4 \%)$ & $15(24.2 \%) / 8(12.9 \%)$ & 0.478 \\
\hline Age $\geq 65$ years & $20(54.1 \%)$ & $17(45.9 \%)$ & 0.067 \\
\hline Transformation into AML & $6(50 \%)$ & $6(50 \%)$ & 0.240 \\
\hline LDH $>220 \mathrm{~g} / \mathrm{dL}$ & $23(60.5 \%)$ & $15(39.5 \%)$ & 0.416 \\
\hline Mortality & $17(51.5 \%)$ & $16(48.5 \%)$ & \\
\hline
\end{tabular}


Tab. 2. Overall survival analysis of the cases according to clinical and laboratory findings.

\begin{tabular}{|c|c|c|c|}
\hline & $\begin{array}{c}\text { Overall survival } \\
\text { (mean } \pm \text { standard } \\
\text { deviation) }\end{array}$ & $\begin{array}{l}95 \% \text { Confidence } \\
\text { Interval }\end{array}$ & $\begin{array}{c}\mathrm{p} \\
\text { (Logrank) }\end{array}$ \\
\hline \multicolumn{4}{|l|}{ Age } \\
\hline$<65$ years old & $63.9 \pm 4.9$ months & $54.33-73.59$ & \multirow[t]{2}{*}{0.621} \\
\hline$\geq 65$ years old & $45.8 \pm 6.1$ months & $33.76-57.86$ & \\
\hline \multicolumn{4}{|l|}{ Gender } \\
\hline Male & $61.2 \pm 4.5$ months & $44.66-82.76$ & \multirow[t]{2}{*}{0.219} \\
\hline Female & $63.7 \pm 9.7$ months & $51.35-71.06$ & \\
\hline \multicolumn{4}{|l|}{ PLR } \\
\hline$\leq 46$ & $59.9 \pm 15.2$ months & $30.05-89.75$ & \multirow[t]{2}{*}{0.596} \\
\hline$>46$ & $63.4 \pm 4.8$ months & $53.8-72.9$ & \\
\hline \multicolumn{4}{|c|}{ Multilineage dysplasia } \\
\hline Positive & $49.8 \pm 6.8$ months & $36.5-63.2$ & \multirow[t]{2}{*}{0.001} \\
\hline Negative & $75.3 \pm 4.5$ months & $66.3-84.3$ & \\
\hline \multicolumn{4}{|c|}{ AML transformation } \\
\hline Positive & $27.1 \pm 5.9$ months & $15.5-38.7$ & \multirow[t]{2}{*}{0.003} \\
\hline Negative & $67.5 \pm 4.5$ months & $58.7-76.4$ & \\
\hline \multicolumn{4}{|l|}{ Platelet count } \\
\hline$\leq 50 \times 10^{9} / \mathrm{L}$ & $20.14 \pm 5.37$ months & $9.6-30.6$ & \multirow{2}{*}{0.021} \\
\hline$>50 \times 10^{9} / \mathrm{L}$ & $65.5 \pm 4.5$ months & $56.6-74.4$ & \\
\hline \multicolumn{4}{|l|}{ Leukocyte count } \\
\hline$\leq 4 \times 10^{9} / \mathrm{L}$ & $56.41 \pm 7.31$ months & $42.07-70.75$ & \multirow[t]{2}{*}{0.546} \\
\hline$>4 \times 10^{9} / \mathrm{L}$ & $66.34 \pm 5.57$ months & $55.41-77.27$ & \\
\hline \multicolumn{4}{|c|}{ Ring sideroblasts in bone marrow } \\
\hline Positive & $60.3 \pm 7.0$ months & $46.5-74.1$ & \multirow[t]{2}{*}{0.758} \\
\hline Negative & $65.7 \pm 5.7$ months & $54.4-77.0$ & \\
\hline \multicolumn{4}{|c|}{ Fibrosis in bone marrow } \\
\hline Positive & $61.2 \pm 6.1$ months & $49.2-73.2$ & \multirow[t]{2}{*}{0.710} \\
\hline Negative & $64.8 \pm 7.0$ months & $50.9-78.7$ & \\
\hline \multicolumn{4}{|l|}{ Hemoglobin } \\
\hline$\leq 8 \mathrm{~g} / \mathrm{dL}$ & $62.8 \pm 4.8$ months & $53.3-72.2$ & \multirow[t]{2}{*}{0.605} \\
\hline$>8 \mathrm{~g} / \mathrm{dL}$ & $70.5 \pm 10.5$ months & 49.9-91.08 & \\
\hline \multicolumn{4}{|l|}{ LDH } \\
\hline$\leq 220 \mathrm{~g} / \mathrm{dL}$ & $54.6 \pm 7.9$ months & $39.0-70.16$ & \multirow[t]{2}{*}{0.293} \\
\hline$>220 \mathrm{~g} / \mathrm{dL}$ & $68.7 \pm 5.4$ months & $58.0-79.4$ & \\
\hline \multicolumn{4}{|c|}{ Percentage of blasts in bone marrow } \\
\hline$\leq 5 \%$ & $64.2 \pm 5.1$ months & $54.0-74.3$ & \multirow{2}{*}{0.210} \\
\hline$>5 \%$ & $53.4 \pm 9.6$ months & $34.4-72.3$ & \\
\hline
\end{tabular}

of $\leq 46(p=0.005)$. The PLR cut-off values and clinical and laboratory findings are presented in Table 1.

The mean survival time of MDS cases in our study was $62.8 \pm 4.5$ months. The impact of dysplasia in two and/or more series, transformation into acute leukemia, ring sideroblasts in bone marrow, fibrosis in the bone marrow, anemia, thrombocytopenia, increased LDH value, and PLR > 46 on survival were evaluated. The comparisons of overall survival according to clinical and laboratory findings are presented in Table 2. The decreased survival was found to be significantly associated with the presence of dysplasia in two and/or more series $(\mathrm{p}=0.001)$ (Fig. 2), transformation into acute leukemia $(\mathrm{p}=0.003)$ (Fig. 3), and thrombocytopenia $\left(<50 \times 10^{9} / \mathrm{L} ; \mathrm{p}=0.021\right)$ (Fig. 4). There was no significant correlation between the survival and presence of ring sideroblasts in bone marrow $(\mathrm{p}=0.863)$, fibrosis in bone marrow ( $\mathrm{p}=0.710)$, anemia $(\mathrm{p}=0.605)$, elevated LDH levels $(\mathrm{p}=0.293)$, and PLR of $>46(\mathrm{p}=0.596)$. The analysis of overall survival according to clinical and laboratory findings is presented in Table 2.

The mortality rate of MDS with multilineage dysplasia was increased five times (95\% CI $0.4-3.35$; $\mathrm{p}=0.003)$. The presence of thrombocytopenia $\left(<50 \times 10^{9} / \mathrm{L}\right)$ increased the mortality eight times ([95\% CI 0.42-0.88], $\mathrm{p}=0.035$ ). Acute leukemia transformation was found to be associated with mortality which was increased seven times (95\% CI [0.04-0.65], $\mathrm{p}=0.01)$.
Receiver operating characteristic curves (ROC) were used to obtain cut-off levels of lymphocyte count, platelet count, and PLR for mortality. Cut-off level of $361 / \mu \mathrm{L}$ lymphocyte count was established for mortality $(\mathrm{p}=0.005)$. The area under ROC curve for lymphocyte count was 0.236 with a cut-off level of $361 / \mu \mathrm{L}$, while sensitivity and specificity were $69 \%$ and $88 \%$, respectively. The cut-off level of platelet count could not be determined for mortality $(p>0.05)$. A cut-off value of 46 was established for PLR for mortality ( $p=0.015$ ). The calculated cut-off levels had the highest sensitivity compared to the other cut-off levels. The area under ROC curve for PLR was 0.680 with a cut-off value of 46 with sensitivity and specificity of $89.7 \%$ and $75.8 \%$, respectively (Fig. 1). A cut-off value of $\leq 46$ for PLR was significantly associated with dysplasia in bone marrow $(\mathrm{p}=0.008)$ and mld-MDS $(\mathrm{p}=0.005)$. Among the 26 patients diagnosed as MDS with multilineage serial dysplasia, 15 (65.2\%) patients had a PLR cut-off value of $\leq 46(\mathrm{p}=0.005)$. Among the 36 patients diagnosed with other MDS subtypes, 8 (34.2\%) patients had a PLR cut-off level

\section{Discussion}

According to the results of our study, the cases with decreased platelet-to-lymphocyte ratio were associated with MDS subtype with dysplasia in multilineage series in univariate analyzes. However, there was no significant relationship with overall survival. Also, according to multivariate analysis, the overall survival was decreased in patients with thrombocytopenia, transformation to acute myeloid leukemia, and multiple series dysplasia.

The mechanism, by which the immune system can influence prognosis in MDS has not been fully elucidated. Interestingly, chronic immunostimulation involved in the pathogenesis of MDS through proinflammatory cytokines, and inflammatory environment in the bone marrow microenvironment have been shown to cause dysplasia in MDS $(18,19)$.

In addition, it has been shown that changes in the functions of T-regulatory lymphocyte cells may be a parameter that predicts disease progression and bone marrow failure in the early stage 


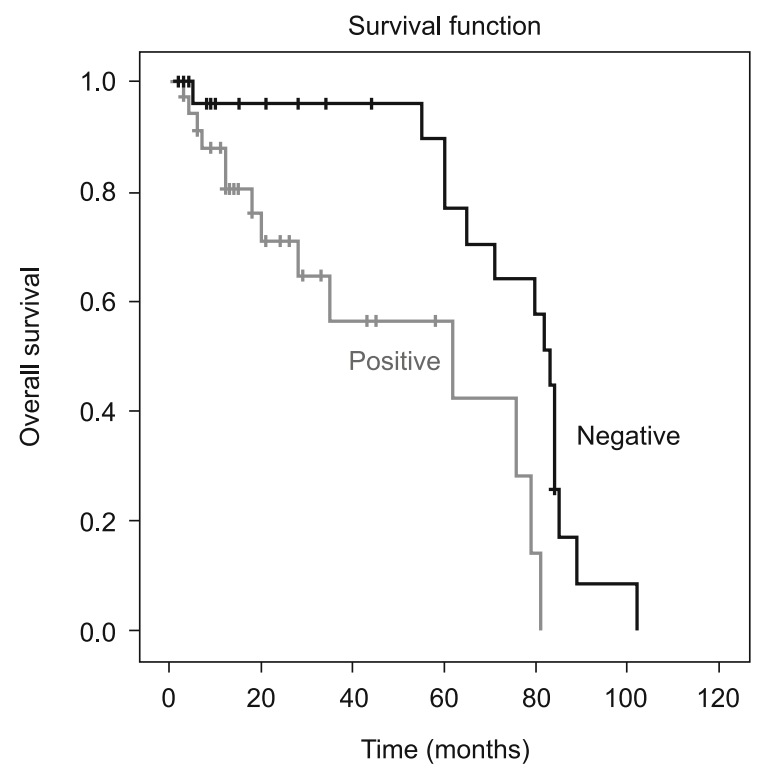

The presence of dysplasia in 2 and/or more series

Fig. 2. Kaplan-Meier curves for survival for presence of dysplasia in two and/or more series in MDS cases.

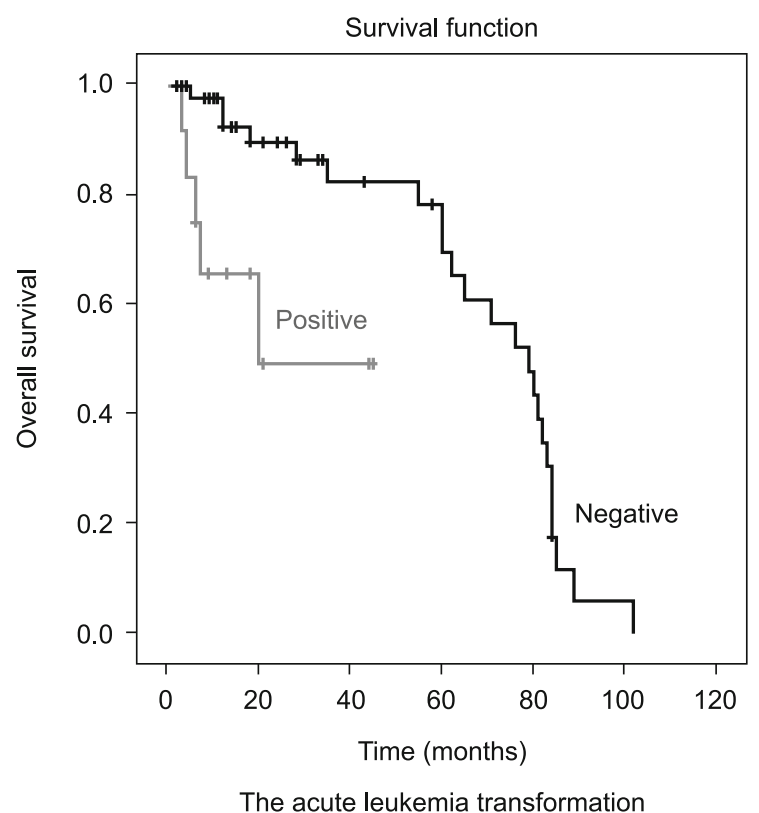

Fig. 3. Kaplan-Meier curves for survival for presence of transformation into acute leukemia in MDS cases.

of MDS (20). Some studies suggest that a defect in T-regulatory lymphocytes in the low-risk MDS patient group supports dysplastic clone selection (21). Furthermore, it has been suggested that increased T-regulatory lymphocyte count promotes leukemic transformation (22). The inflammatory response is associated with cancer pathophysiology in which inflammation markers such as lymphocyte count, platelet count, c-reactive protein, and hypoalbuminemia have been investigated in many cancers as well as

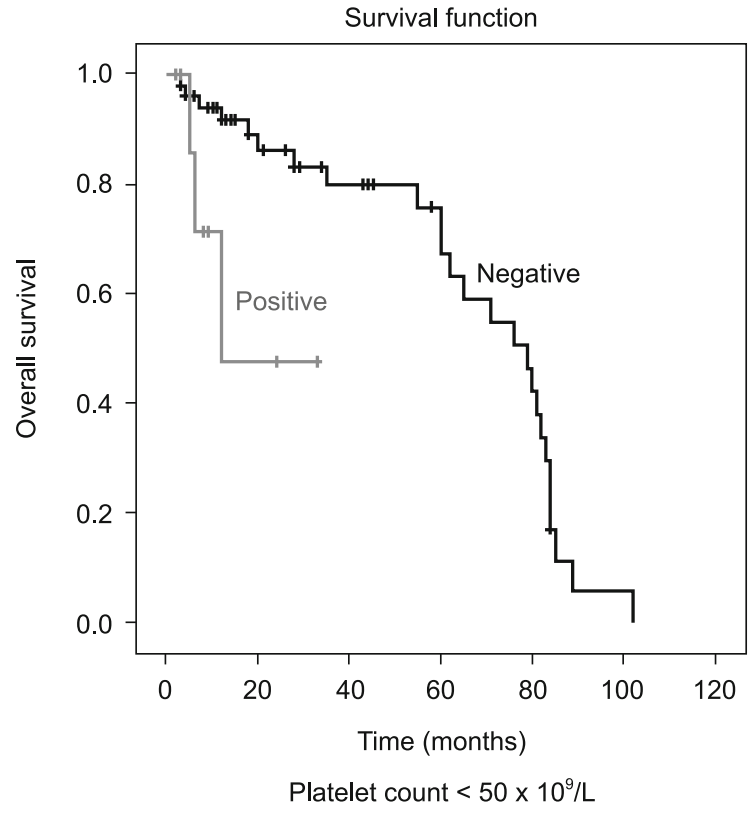

Fig. 4. Kaplan-Meier curves for survival for presence of thrombocytopenia in MDS cases.

in MDS (23). Both low platelet count and leukopenia have been associated with poor prognosis in MDS patients due to impaired pathophysiology (9). In both bone marrow and peripheral blood, the half-life of blood cell lines of all three series was shortened and the function was impaired (2). We could not find any data about the effect of platelet-to-lymphocyte ratio as an inflammatory marker of prognosis in MDS cases. According to our data, we found a significant relationship between mld-MDS subtype and low PLR values. Multilineage dysplasia and blast percentage are important prognostic factors in the classification of WHO when evaluating bone marrow morphology in MDS patients (17). In the current study, there were 26 (41.9\%) cases with MDS with multilineage dysplasia (mld-MDS), while the expected distribution of the mldMDS subtype is approximately $70 \%$, and in our case series, it was $41.9 \%$. The rate of MDS with single lineage dysplasia was 27.7 $\%$, which was higher than the expected rate according to literature. The lower PLR value in mld-MDS cases may be related to the predominance of the defect in the thrombopoiesis part for the expected dysplasia in at least two series in these cases.

The reactive thrombocytosis is known to be associated with systemic inflammatory response. Therefore, many published studies have investigated the effect of PLR on hematologic and nonhematologic malignancies and reported that increased PLR is associated with poor prognosis and negative impact on survival (24-27). However, low PLR in multiple myeloma, one of the hematologic malignancies involving suppression of thrombopoiesis caused by inflammatory effect, was found to be associated with poor prognosis (28). This is a known effect of disease pathophysiology in MDS. Although the number of patients in our current data was limited, PLR was not found to be associated with survival or leukemic transformation in MDS. 
422-427

Thrombocytopenia has been associated with a decrease in overall survival in many studies, which is consistent with our results. The rate of patients with severe thrombocytopenia who required platelet transfusion at the time of diagnosis was $8 \%$. The low platelet count in patients with MDS reflects a reduced bone marrow reserve and function. Therefore, low platelet count is considered a poor prognostic factor in many classification systems $(4,29)$. Another study stated that both low platelet count at the time of diagnosis and rapid decrease in platelet count during follow-up were poor prognostic factors (30). The finding of severe thrombocytopenia, especially in advanced stages such as RAEB-1 and RAEB-2, is more frequently expected (31).

The transformation to acute myeloid leukemia is a complication of MDS that leads to shortened survival in cases, while cases with transformation to acute myeloid leukemia are more likely to be refractory to treatment (2). In our series, patients with acute leukemia transformation had a significantly shortened survival rate. MDS cases with multiple series dysplasia are associated with decreased overall survival and are a risky group for leukemic transformation. Our data are also consistent with published data. Multilineage dysplasia in MDS has unfavorable survival compared to unilineage dysplasia. The published data show that cases with less cytopenia and less dysplasia at diagnosis have superior overall and progression-free survival (32).

\section{Conclusion}

According to our results, the decreased PLR was associated with mld-MSD subtype but not with survival in MDS cases. Although the number of patients was limited, we wanted to report our results because of the limited data on PLR values in MDS. The relationship between dysplasia and peripheral cytopenia in MDS has not been fully clarified. We believe that more comprehensive studies are needed to determine the value of PLR.

\section{References}

1. Pang WW, Pluvinage JV, Price EA, Sridhar K, Arber DA, Greenberg PL, Schrier SL, Park CY, Weissman IL. Hematopoietic stem cell and progenitor cell mechanisms in myelodysplastic syndromes. Proc Natl Acad Sci U S A. 2013 Feb 19;110 (8): 3011-6. doi: 10.1073/pnas.1222861110.

2. Goldberg SL, Chen E, Corral M, Guo A, Mody-Patel N, Pecora AL, Laouri M. Incidence and clinical complications of myelodysplastic syndromes among United States Medicare beneficiaries. J Clin Oncol. 2010 Jun 10;28 (17): 2847-52. doi: 10.1200/JCO.2009.25.2395.

3. Schanz J, Tüchler H, Solé F, Mallo M, Luño E, Cervera J, Granada I, Hildebrandt B, Slovak ML, Ohyashiki K et al. New comprehensive cytogenetic scoring system for primary myelodysplastic syndromes (MDS) and oligoblastic acute myeloid leukemia after MDS derived from an international database merge. J Clin Oncol. 2012 Mar 10;30 (8): 820-9. doi: 10.1200/JCO.2011.35.6394.

4. Greenberg PL, Tuechler H, Schanz J, Sanz G, Garcia-Manero G, Solé F, Bennett JM, Bowen D, Fenaux P, Dreyfus F, et al. Revised international prognostic scoring system for myelodysplastic syndromes. Blood. 2012 Sep 20;120 (12): 2454-65.
5. Malcovati L, Germing U, Kuendgen A, Della Porta MG, Pascutto C, Invernizzi R, Giagounidis A, Hildebrandt B, Bernasconi P, Knipp $\mathrm{S}$ et al. Time-dependent prognostic scoring system for predicting survival and leukemic evolution in myelodysplastic syndromes. J Clin Oncol. 2007 Aug 10;25 (23): 3503-10.

6. Kantarjian H, O'Brien S, Ravandi F, Cortes J, Shan J, Bennett JM, List A, Fenaux P, Sanz G, Issa JP et al. Proposal for a new risk model in myelodysplastic syndrome that accounts for events not considered in the original International Prognostic Scoring System. Cancer. 2008 Sep 15;113 (6): 1351-61. doi: 10.1002/cncr.23697.

7. Garcia-Manero G, Shan J, Faderl S, Cortes J, Ravandi F, Borthakur G, Wierda WG, Pierce S, Estey E, Liu J, et al. A prognostic score for patients with lower risk myelodysplastic syndrome. Leukemia. 2008 Mar;22 (3): 538-43.

8. Jacobs NL, Holtan SG, Porrata LF, Markovic SN, Tefferi A, Steensma DP et al. Host immunity affects survival in myelodysplastic syndromes: Independent prognostic value of the absolute lymphocyte count. Am J Hematol. 2010;85 (3): 160.

9. Breccia M, Latagliata R, Cannella L, Carmosino I, Santopietro M, Loglisci G, Federico V, Alimena G et al. Refractory cytopenia with unilineage dysplasia: analysis of prognostic factors and survival in 126 patients. Leuk Lymphoma. 2010;51 (5): 783.

10. Roxburgh CS, McMillan DC. Role of systemic inflammatory response in predicting survival in patients with primary operable cancer. Future Oncol 2010;6:149-63.

11. Wagner DD. New links between inflammation and thrombosis. Arterioscler Thromb Vasc Biol 2005;25:1321-4.

12. Shi X, Zheng Y, Xu L, Cao C, Dong B, Chen X. The inflammatory cytokine profile of myelodysplastic syndromes: A meta-analysis. Medicine (Baltimore). 2019 May;98 (22): e15844.

13. Wongrakpanich S, George G, Chaiwatcharayut W, Biso S, Candelario N, Mittal V, et al. The prognostic significance of neutrophil-to-lymphocyte and platelet-to-lymphocyte ratios in patients with multiple myeloma. J Clin Lab Anal 2016;30:1208-13.

14. Wang S, Ma Y, Sun L, Shi Y, Jiang S, Yu K, Zhou S. Prognostic Significance of Pretreatment Neutrophil/Lymphocyte Ratio and Platelet/Lymphocyte Ratio in Patients with Diffuse Large B-Cell Lymphoma. Biomed Res Int. 2018 Dec 12;2018:9651254. doi: 10.1155/2018/9651254. eCollection 2018.

15. Reddy JP, Hernandez M, Gunther JR, Dabaja BS, Martin GV, Jiang W, Akhtari M, Allen PK, Atkinson BJ, Smith GL, Pinnix CC, Milgrom SA, Abou Yehia Z, Osborne EM, Oki Y, Lee H, Hagemeister F, Fanale MA. Pre-treatment neutrophil/lymphocyte ratio and platelet/ lymphocyte ratio are prognostic of progression in early stage classical Hodgkin lymphoma. Br J Haematol. 2018 Feb;180 (4): 545-549. doi: 10.1111/bjh.15054. Epub 2017 Dec 21.

16. Demirci NS, Ozdemir NY, Erdem GU, Bozkaya Y, Yazici O, Zengin N. Preoperative platelet-to-lymphocyte ratio is a predictor of prognosis in patients with ampullary carcinoma. Bratisl Lek Listy. 2018;119 (3): 180-186. doi: 10.4149/BLL_2018_033.

17. Arber DA, Orazi A, Hasserjian R, Thiele J, Borowitz MJ, Le Beau MM, Bloomfield CD, Cazzola M, Vardiman JW. The 2016 revision to the World Health Organization classification of myeloid neoplasms and acute leukemia. Blood. 2016 May 19;127 (20): 2391-405. doi: 10.1182/ blood-2016-03-643544. 
18. Kristinsson SY, Björkholm M, Hultcrantz M, Derolf ÅR, Landgren O, Goldin LR: Chronic immune stimulation might act as a trigger for the development of acute myeloid leukemia or myelodysplastic syndromes. J Clin Oncol 2011; 29: 2897-2903.

19. Meirow Y, Kanterman J, Baniyash M: Paving the road to tumor development and spreading: myeloid-derived suppressor cells are ruling the fate. Front Immunol 2015; 6: 523.

20. Alfinito F, Sica M, Luciano L, Della Pepa R, Palladino C, Ferrara I et al. Immune dysregulation and dyserythropoiesis in the myelodysplastic syndromes. Br J Haematol 2010; 148: 90-98.

21. Kordasti SY, Ingram W, Hayden J, Darling D, Barber L, Afzali B et al. CD4+CD25high Foxp3+ regulatory T cells in myelodysplastic syndrome (MDS). Blood 2007; 110: 847-850

22. Kotsianidis I, Bouchliou I, Nakou E, Spanoudakis E, Margaritis D, Christophoridou AV et al. Kinetics, function and bone marrow trafficking of CD4+CD25+FOXP3+ regulatory T cells in myelodysplastic syndromes (MDS). Leukemia 2009; 23: 510-518.

23. Sevindik OG, Guc Z, Kahraman S, Medeni Solmaz S, Katgi A, Acar C, Alacacioglu I, Piskin O, Ozsan GH, Demirkan F, Undar B, Ozcan MA. Hypoalbuminemia is a surrogate biomarker of poor prognosis in myelodysplastic syndrome even when adjusting for comorbidities. Leuk Lymphoma. 2015;56 (9): 2552-5. doi: 10.3109/10428194.2015.1014362.

24. Salman T, Kazaz SN, Varol U, Oflazoglu U, Unek IT, Kucukzeybek Y, et al. Prognostic value of the retreatment neutrophil-to-lymphocyte ratio and platelet-to-lymphocyte ratio for patients with neuroendocrine tumors: An izmir oncology group study. Chemotherapy 2016;61:281-6.

25. Baranyai Z, Krzystanek M, Jósa V, Dede K, Agoston E, Szász AM et al. The comparison of thrombocytosis and platelet-lymphocyte ratio as potential prognostic markers in colorectal cancer. Thromb Haemost 2014;111:483-90.
26. Jung SH, Kim JS, Lee WS, Oh SJ, Ahn JS, Yang DH, et al. Prognostic value of the inverse platelet to lymphocyte ratio (iPLR) in patients with multiple myeloma who were treated up front with a novel agent-containing regimen. Ann Hematol 2016;95:55-61.

27. Seo J, Kim WS, Kim JS, Kim SJ, Lee JH, Hong JS, Lee GW, Oh SY, Lee JH, Yoon DH, et al. Platelet to lymphocyte ratio (PLR) retains independent prognostic significance in advanced stage marginal zone lymphoma patients treated with rituximab, cyclophosphamide, vincristine, and prednisone combination chemotherapy (R-CVP): Consortium for Improving Survival of Lymphoma trial. Blood Res. 2017 Sep;52 (3): 200-206. doi: $10.5045 /$ br.2017.52.3.200.

28. Solmaz S, Uzun O, Acar C, Sevindik OG, Piskin O, Ozsan HG, et al. Is the platelet-to-lymphocyte ratio a new prognostic marker in multiple myeloma?. J Lab Physicians 2018;10:363-9.

29. Greenberg P, Cox C, LeBeau MM, et al. International scoring system for evaluating prognosis in myelodysplastic syndromes. Blood. 1997;89 (6): 2079 LP-2088.

30. Itzykson R, Smith A, Fenaux P, et al. Prognostic value of early drop in platelets in lower-risk MDS. A sub-study from the European Leukemianet Lower-Risk MDS (EUMDS) Registry. Leukemia Research. 2017;55:S10 S11 https://doi.org/10.1016/S0145-2126(17)301327.

31. Tang Y, Zhang X, Han S, Chu T, Qi J, Wang H, Tang X, Qiu H, Fu C, Ruan C, Wu D, Han Y. Prognostic Significance of Platelet Recovery in Myelodysplastic Syndromes With Severe Thrombocytopenia. Clin Appl Thromb Hemost 2018; 8:1076029618802363. doi: $10.1177 / 1076029618802363$.

32. Malcovati L, Della Porta MG, Pascutto C, Invernizzi R, Boni M, Travaglino E et al. Prognostic Factors and life expectancy in Myelodysplastic Syndromes classified according to the WHO criteria: A basis for clinical decision making. J Clin Oncol 2005; 23: 7594-7603.

Received January 27, 2020. Accepted March 2, 2020. 